\title{
LA PROYECCIÓN DE TRASMUNDOS Y EL PROBLEMA DE LA MUERTE DE DIOS ${ }^{1}$
}

The projection of afterworld and the problem of the death of God

\author{
Ana Escríbar W. \\ Departamento de Filosofía \\ Universidad de Chile \\ anita.escribarwicks@gmail.com
}

\section{INTRODUCCION}

Resulta evidente que en nuestro mundo se da una marcada ausencia de Dios; aun cuando queden individuos y grupos que mantienen la fe en su existencia, él no actúa ya como fundamento de una cultura que no parece sentir la necesidad de su presencia, ni en relación a valores e ideales cuya vigencia queda absolutamente cuestionada por las metas reales de la humanidad contemporánea.

El eclipse de Dios dentro del horizonte de la cultura actual fue anunciado con acentos apocalípticos por Nietzsche; este filósofo, que ha sido descrito como el profeta de la muerte de Dios, ubica las causas últimas de este fenómeno en el carácter metafísico del pensamiento occidental, Curiosamente, Mircea Eliade, el gran historiador y fenomenólogo de las religiones, describe un fenómeno similar como parte integrante de la religiosidad arcaica y parece discernir las condiciones determinantes de dicho proceso en la esencia misma de la religiosidad que - para él- se identifica con lo que podríamos designar como tendencia metafísica.

Analizar la verdadera naturaleza de dicha tendencia y poner al descubierto sus posibles relaciones con el moderno proceso de la "muerte de Dios" es el objetivo del presente trabajo; se recurrirá para ello a los planteamientos de Nietzsche referentes al nihilismo, a la

\footnotetext{
${ }^{1}$ Publicado en II Jornadas Interdisciplinarias 1993.Páginas 123 - 133
} 
descripción que Eliade hace de la esencia del fenómeno religioso y a los análisis de Paul Ricoeur en relación al posible valor de verdad del discurso poético y religioso.

\section{1.- NIETZSCHE, NIHILISMO Y MUERTE DE DIOS}

Nietzsche usa el término nihilismo para designar lo que le parece ser el rasgo fundamental de su época; escuchada desde hoy, su voz adquiere resonancias proféticas, puesto que lo que él describe parece corresponder exactamente a lo que podríamos considerar como esencial en el momento actual.

Tal como él lo entiende, el nihilismo significa la pérdida de vigencia de los valores que hasta ese momento se presentaban como absolutos, la falta de respuesta al por qué y al para qué del sufrimiento y de la vida, la total carencia de un sentido que ilumine la existencia. Más aún, implica el íntimo convencimiento acerca de la total ilegitimidad de cualquier esperanza en relación a la posibilidad de que otros valores y otro sentido pudieran venir a reemplazar a los que actualmente están en crisis. El nihilismo así entendido se identifica para Nietzsche con lo que él llama la "muerte de Dios"; esta última, por consiguiente, no hace referencia sólo a un supuesto ateísmo predominante en la actualidad, sino a la total desaparición de lo que representaba para nuestra cultura el fundamento último, aquello a lo que la metafísica desde Platón en adelante ha hecho referencia con los términos de "mundo suprasensible"

Dicho nihilismo no representa para Nietzsche un fenómeno puntual. Antes bien, aquel sería consustancial a nuestra cultura, constituiría la ley interna de su desarrollo. El pensamiento occidental es - dice el filósofo esencialmente metafísico y por tal entiende la permanente distinción entre ser y apariencia que lo ha caracterizado a partir de sus inicios filosóficos en Grecia y religiosos en el judeo-cristianismo.

Afirma Nietzsche que la mencionada distinción significa la desvalorización del devenir y del mudo sensible en función de la eternidad inmóvil del ser supuestamente verdadero; significa también la negación de la vida de aquí y de ahora en pro de otra que se dice mejor y que, para ser alcanzada, exige el absoluto rechazo de los rasgos esenciales de la primera. 
Esta cultura -que nacería al morir el sentido trágico en manos de Sócrates- valora por sobre todo el conocimiento; tiene una confianza absoluta en el poder de la razón y hace residir el sentido de la vida en la paulatina solución de todos los enigmas, en el creciente desvelamiento de la verdad o, lo que es lo mismo, en el gradual descubrimiento de los rasgos esenciales del ser que se oculta tras la apariencia. La verdad, entonces constituye para ella el valor fundamental.

Ahora bien, ese culto a la verdad así entendida y el correspondiente carácter metafísico de nuestra cultura configuran, según Nietzsche, las condiciones que determinan que el nihilismo resida germinalmente en su seno desde sus comienzos. Porque dicho culto, con su inherente tendencia desenmascaradora -raíz de nuestra ciencia terminará por dejar al descubierto la naturaleza ilusoria del supuesto mundo verdadero que aportaba el fundamento de la apariencia. Esta última, lo único que nos queda como producto final del proceso en pos de la verdad, llega a ser efectivamente nada cuando pierde aquello que la mantenía por lo menos como apariencia: el mundo suprasensible y su fundamento divino.

En esta forma, la historia del pensamiento occidental que es historia de la metafísica se identificaría con el proceso de desarrollo del nihilismo, con el proceso de la muerte de Dios. Nuestra época, con su ya explícita crisis de valores, estaría llevando dicho recorrido a su término. Sus causas -como hemos visto- se remontarían a los orígenes de nuestra cultura residirían, en la tendencia metafísica que la caracteriza, que en el fondo es una tendencia a la nada, puesto que se traduce en la proyección de un trasmundo ilusorio, nada que es presentada como el ser verdadero, meta y sentido de la existencia.

De acuerdo a lo anterior, desde la perspectiva nietzscheana el nihilismo y la proyección de trasmundos están íntimamente relacionados. La búsqueda de una trascendencia, que llamaríamos trasmundana, sería en alguna medida causa y síntoma del nihilismo; causa por las razones ya expuestas, síntoma, porque pone de manifiesto la tendencia a la nada propia de una voluntad débil, incapaz de mirar de frente a la vida, de comprenderla en su esencia como voluntad de poder. 
La superación del nihilismo, por consiguiente, pasaría por la superación de la metafísica entendida como distinción entre ser y apariencia; exigiría el desenmascaramiento de la nada que se oculta tras el supuesto ser verdadero, impondría la renuncia al trasmundo.

Exigiría poner en la tierra el fundamento del esencial del sentido, el establecimiento de una trascendencia en la inmanencia, de una meta terrenal.

Esto es lo que intenta la nueva meta y la nueva valoración propuestas por Nietzsche, vale decir, el surgimiento del superhombre y el retorno. El superhombre o ese hombre que es nuevo porque no necesita ya de trasmundos desde que se reconoce a sí mismo, a su voluntad de poder, como fuente del sentido y del valor. El eterno retorno, nuevo criterio valórico de ese hombre nuevo que -a diferencia del metafísico- ama tanto la vida que quiere que cada instante vuelva una y mil veces en la eternidad de un devenir circular.

\section{2.- MIRCEA ELIADE, LA ESENCIA DEL FENÓMENO RELIGIOSO Y EL RETIRO DEL SER SUPREMO EN EL MUNDO ARCAICO.}

De acuerdo a lo expuesto y desde la perspectiva nietzscheana, la tendencia metafísica representa una especie de enfermedad contraída por el hombre a partir del momento en que Sócrates da muerte a la tragedia y crea el sentido teórico, caracterizado también por el culto a la verdad antes descrito.

En cambio Miercea Eliade, apoyándose en el abundante acopio de datos obtenido en sus investigaciones sobre las religiones arcaicas, ve en la tendencia metafísica un rasgo esencial del espíritu humano. Esta se expresaría en la necesidad del hombre primitivo de vivir en íntimo contacto con lo sagrado, como consuelo ante lo que el autor llama el "terror a la historia", vale decir, como una forma de protección frente a la conciencia de la propia finitud. Tal necesidad se pondría de manifiesto en la universalidad del mito del eterno retorno en dichas religiones; en este último, se expresa la convicción acerca de la 
posibilidad de "salvación" con respecto al tiempo real o tiempo histórico mediante la periódica reinserción ritual en el momento privilegiado de la cosmogonía.

Por otra parte, esta misma necesidad de situarse en lo sagrado parece empujar al hombre por el camino de lo que Eliade llama la "hierofanización "creciente. Consiste esta en la sacralización progresiva, mediante ritos cosmogónicos, de los distintos espacios y conductas abarcados por el quehacer humano; en esta forma, toda actividad llega a revestirse de sacralidad al cumplirse de acuerdo a un arquetipo establecido in illo tempore por la correspondiente creación divina.

Como resultado de este proceso de hierofanización creciente la naturaleza se puebla de dioses y diosas que presiden cada uno de los aspectos de la vida y cada uno de los ámbitos del mundo. Frente a esta proliferación de divinidades menores con las que se establece un nutrido intercambio, el Ser Supremo abandona el escenario, se retira al séptimo cielo y se convierte en un Dios ocioso que es recordado sólo con motivo de grandes Catástrofes naturales o históricas.

Así, la hierofanización o sacralización creciente, emanada de la necesidad del ser humano de vivir en intimo contacto con lo sagrado, trae consigo lo que podríamos considerar la versión arcaica del muy moderno proceso de la muerte de Dios. El eclipse de la presencia del ser Supremo parece vincularse inevitablemente con la tendencia metafísica que podríamos interpretar como el permanente esfuerzo del hombre por descubrir un sentido para su vida relacionando con lo eterno su efímera duración.

Como podemos constatar, se produce una cierta cercanía entre los planteamientos del moderno profeta del nihilismo y los del fenomenólogo de las religiones; a pesar de la discrepancia con respecto al carácter de enfermedad histórica o de rasgo humano esencial que uno y otro atribuyen respectivamente a la tendencia metafísica, ambos relacionan con ella el fenómeno de la muerte de Dios. Para Nietzche ésta es producto, en último término, de la proyección filosófico-religiosa de trasmundos; para Eliade, es consecuencia del trasmundo que surge cuando el hombre arcaico -en su deseo de situarse en intimo contacto con lo sagrado- exilia a Dios fuera de un mundo que ha poblado de divinidades más accesibles y, en esa misma medida, más manipulables. 
Ahora bien, Eliade afirma que la necesidad de consuelo frente al "terror a la historia" que empuja al hombre a la búsqueda del ser verdadero o, lo que es lo mismo, a situarse en el contacto más íntimo posible con lo sagrado, es inherente a todo hombre. Ella, por consiguiente, y ésta será la tesis sustentada en el presente trabajo, debería presentar formas específicas de expresión en el mundo moderno, las que podrían tener efectos equivalentes a los esa tendencia creadora de dioses que culmina con el eclipse del ser supremo en el mundo arcaico.

\section{3.- PAUL RICOEUR Y LA POSIBLE VERDAD DE LOS DISCURSOS POÉTICO Y RELIGIOSO}

A menudo se ha considerado en nuestra época que en la poesía el discurso no hace Otra cosa que celebrarse a sí mismo; tal discurso, por consiguiente, a diferencia del discurso ordinario y del científico, carecería de toda referencia a una realidad exterior al lenguaje y estaría desprovisto por ello de todo posible valor de verdad.

En cambio, Ricoeur plantea que lo que distingue al discurso poético del discurso ordinario y del discurso científico es que éstos tienen un carácter esencialmente descriptivo y, en consecuencia, una referencia directa al mundo circundante o a las entidades de las que se ocupa la ciencia. El primero suspende esa referencia directa, pero lo hace en pro de un apuntar más profundo, de una referencia que podríamos llamar de segundo grado, tendiente a desplegar ante la mirada del hombre posibles nuevas maneras de ser o de habitar en el mundo.

En esta forma, el discurso poético, lejos de ser meramente autoreferente, pone de manifiesto algo que estaba oculto; ejerce, pues, una función reveladora que ejemplificaría el tipo de verdad-manifestación contrapuesto, o si se quiere complementario, al de verdadadecuación correspondiente al discurso científico, que concuerda con el criterio de 
verificación empírica propio de la ciencia y que ha impuesto su presencia excluyente en la cultura actual.

Ahora bien, esa función reveladora del discurso poético se enraizaría en la especial riqueza propia de la imaginación creadora, cuyo núcleo está dado por la metáfora. Esta consistiría en una "predicación extravagante" mediante la cual se pone en relación significados antes ajenos entre sí. Tal serla el caso, por ejemplo, cuando se dice que "la naturaleza es como un templo con pilares vivientes".... Lo que la metáfora hace es producir una nueva pertinencia a partir de la llamativa impertinencia del sentido literal; dicha nueva pertinencia pone de manifiesto una cierta cercanía o similitud entre los términos en cuestión, que se hace evidente a partir de la metáfora, en lugar de ser anterior a ella y explicar así su nacimiento.

La metáfora, por otra parte, se nutre de algo más profundo, que no es puro logos y en relación a lo cual ella representa la porción semántica. Se trata del símbolo o fundamento del sentido, que es interpretado por metáfora; aquel tiene tres zonas de emergencia en las que la palabra se intersecta con una especie de fuerza o potencia que la trasciende y la promueve: el mundo de lo onírico estudiado por el sicoanálisis, el de las manifestaciones cósmicas de lo sagrado estudiado por la fenomenología de las religiones y el de lo que "hay que decir" al que se enfrenta la inspiración del poeta. El símbolo-dice Ricoeur- "da que pensar"; esto es, porque apunta hacia algo otro que a través suyo se manifiesta y se oculta, origina un proceso de interpretación iniciado por la metáfora que se esfuerza por "decirlo", por traducir íntegramente su sentido, sin lograrlo jamás totalmente.

En consecuencia, el discurso poético nos dice efectivamente algo acerca de la realidad, algo que no puede ser dicho por el lenguaje directamente descriptivo, limitado por su referencia a los objetos de nuestra manipulación. Con la creación metafórica nos dice analógicarnente como que son las cosas de lo que podríamos llamar el mundo vital, el mundo de nuestro arraigo originario, previo a la escisión sujeto-objeto propia de la actitud teórica.

En relación al discurso religioso distingue Ricoeur dos niveles: el primario o preconceptual, en el que se expresa directamente la experiencia religiosa de una comunidad y un segundo, ya trabajado, que presenta un carácter teológico-filosófico. Ese discurso religioso primario, 
que en la tradición judeo-cristiana se ejemplifica en los géneros literarios propios del Antiguo y del Nuevo Testamento, formaría parte integrante del discurso poético. Como éste, carecería de la función descriptiva propia de los discursos ordinario y científico y, precisamente por ello, participaría de la misma función reveladora de aquel, desplegando ante la mirada del hombre nuevos modos posibles de ser o de habitar en el mundo.

Dentro de la señalada pertenencia, habría una especificidad del discurso religioso dada por aquello a lo que apunta: Dios. Este es nombrado diferentemente por cada uno de los géneros literarios constitutivos de las Sagradas Escrituras; es nombrado como Padre, Rey, Pastor, Esposo, Salvador, Juez, etc., constituyéndose en el referente último jamás alcanzado $\mathrm{y}$, por consiguiente, jamás agotado. Como consecuencia de la multiplicidad de las nominaciones contrapuestas provenientes de narraciones, profecías, proverbios, plegarias, himnos, escritos sapienciales, parábolas, epístolas, etc., Dios queda finalmente innombrado, poniéndose de manifiesto la naturaleza inefable de su esencia.

Así, podríamos decir que el discurso religioso primario es aquel discurso poético cuyo referente último, Dios, debido a su absoluta trascendencia en relación a lo dicho en los múltiples modos de decir, arrastra una y otra vez al hombre a una nueva proyección de sus posibilidades como ser en el mundo.

Cumple, pues, con excelencia la función poética o función de revelación, mostrándose como el auténtico modelo de toda poesía, como el paradigma de la verdad-manifestación.

Ahora bien, como decíamos antes, el símbolo da que pensar; ello lo convierte en punto de partida de un proceso de interpretación en el que -más allá del nivel metafórico- se pone de manifiesto una especie de vocación de racionalidad que le es inherente y que se orienta en la dirección de un concepto que aparece como telos.

Dicho proceso se aprecia con gran claridad en el caso de la simbología del mal analizada por Ricoeur. Se describe allí como el hombre jamás ha expresado su experiencia del mal en un lenguaje directo, recurriendo siempre a una simbología que la historia de las religiones despliega hoy ante nuestra mirada Aparece, en primer lugar, la imagen de la mancha correspondiente a una concepción mágica del mal que lo entiende como impureza, como 
algo que en alguna medida nos invade por contagio, desde fuera; luego, en una interpretación del mal que podríamos llamar ética, aparecen las imágenes de la desviación, de la trasgresión, que expresan la percepción del origen del mal como pecado, como distanciamiento frente a Dios; finalmente, para una experiencia ya más interiorizada, aparecen las imágenes del peso y de la carga que traducen el sentimiento de culpabilidad de una conciencia que responde en primer lugar ante sí misma.

Podemos ver que las imágenes descritas se ordenan de acuerdo a dos perspectivas; las que esbozan el mal como algo que el hombre padece, o bien como algo que de alguna manera y en alguna medida tiene en lo humano su punto de emergencia. Se trata de las concepciones trágica y ética del mal que se expresan en dos familias de mitos, contrapuestas entre sí, que reúnen esas imágenes en narraciones que intentan dar respuesta a la pregunta en torno al origen del mal, al porqué del sufrimiento y de la muerte.

De acuerdo al esquema trágico el mal tiene un origen exterior al ser humano; forma parte, incluso, del Dios que lo tienta y lo extravía; representa una especie de destino inexorable que hace presa del hombre por el sólo hecho de llegar éste a la existencia. A tal tipo pertenecen, por ejemplo, el mito órfico del alma exiliada en un cuerpo malo y el de Prometeo.

El otro esquema es el que podríamos llamar antropológico o ético y se ejemplifica centralmente en la narración bíblica de la caída de Adán. Aquí es el hombre quien introduce el mal en el mundo como consecuencia de una libre decisión suya. Adán desobedece a Dios, come el fruto del árbol de la ciencia del bien y del mal y, a partir de este instante simbólico, desaparece la inocencia, se desencadena el sufrimiento, la muerte se constituye en meta insoslayable de la vida.

Ricoeur destaca como, sin embargo, la dualidad de perspectivas en relación al origen del mal se reproduce en el seno de la narración bíblica. En efecto, el mito adánico narra el acto voluntario mediante el cual el primer hombre rompe con el mandato divino, pero describe también la presencia de la serpiente, la seducción que precede a aquella libre decisión. Así, la serpiente introduce dentro de la narración bíblica el elemento central de la concepción trágica del mal, lo que Ricoeur llama "el mal ya allí", el que no comienza con el hombre, 
sino que lo antecede e invade desde fuera. La intromisión subrepticia de este elemento trágico en el mito bíblico estaría indicando que la experiencia humana del mal incluye ambos aspectos contradictorios entre sí; ese sería, precisamente, el motivo por el cual dicha experiencia recurre necesariamente al lenguaje simbólico para expresarse: el símbolo, entonces, dice algo que por su naturaleza no lingüística no puede decirse de otra forma.

Ahora bien, durante los primeros cuatro siglos de nuestra era se producirá el proceso de racionalización en torno al problema del origen del mal cuyo sentido preconceptual está dado en el mito bíblico. Dicho proceso culmina prácticamente con las formulaciones de San Agustín que -surgidas al calor de las exigencias apologéticas de las polémicas con Maniqueo y Pelagio- dan nacimiento al concepto de pecado original, vigente hasta hoy dentro de la dogmática católica. Este incluye dos elementos aparentemente contradictorios entre sí: la idea de herencia casi biológica de una tara o mancha y la de una responsabilidad casi jurídica con respecto a esa tara hereditaria.

Esa contradicción inherente constituye a la noción de pecado original en un seudoconcepto, esto es, en un concepto imposible desde el punto de vista lógico, cuyo verdadero sentido sólo puede ser descifrado a partir del mito que está en sus orígenes. Los elementos contradictorios que el seudo-concepto trata de conciliar responden al intento de racionalizar la conjunción en el relato bíblico de las dos explicaciones míticas - trágica y ética- sobre el origen del mal.

Este ir del símbolo al concepto es exigido por el primero debido al componente inefable que le es propio y que lo constituye en algo que "da que pensar". Por consiguiente, el proceso antes descrito en relación a los mitos en torno al origen del mal debe repetirse en forma inevitable a partir de cada simbología. Así sucede en el caso de Dios, referente último de todos los géneros literarios del Antiguo y Nuevo Testamento; a partir de esas múltiples nominaciones cuya abierta diversidad redundaba en el poético decir "como qué" es la esencia divina en su fundamental indecibilidad, se origina un proceso racionalizador que, olvidando la naturaleza necesariamente analógica de todos esos modos del decir, apunta hacia un concepto que pretende validez lógica. Este proceso de traducción en 
términos teológico-filosóficos del discurso religioso primario es lo que Rudolf Otto describe magistralmente en su libro "Lo Santo", mostrando como a lo largo de dicho proceso han quedado excluidos todos los elementos irracionales incluidos en la experiencia humana de lo que él designa como "Lo Numinoso".

\section{4.- RELACIÓN ENTRE LOS PROCESOS ARCAICO Y MODERNO DE LA "MUERTE DE DIOS"}

Lo que ha sucedido a lo largo del proceso de elaboración teológico-filosófica que hemos descrito es que el discurso religioso al ir abandonando el nivel que describiéramos como primario, ha ido asumiendo cada vez más un carácter especulativo. Se ha analogado, así, a la condición descriptiva propia de los discursos ordinario y científico y ha perdido, en pro de una pretendida verdad-adecuación, la función referencial de segundo grado que lo definía como discurso poético y, por consiguiente, su capacidad reveladora de nuevas formas posibles de habitar en el mundo.

Así podríamos decir que la necesidad de vivir en el más íntimo contacto con lo sagrado asume en la religión histórica y monoteísta que es el cristianismo una dimensión diferente a la que tuviera en las religiones cósmicas; sus consecuencias, sin embargo, serían en alguna medida similares. Esa necesidad buscaría aquí satisfacerse intentando delimitar mediante conceptos -en un esfuerzo por hacerlo comprensible- ese referente último de los múltiples modos del decir poético ejemplificados en las Escrituras. En esta forma, tal como la realidad resulta empobrecida cuando el hombre contemporáneo la reduce a sus aspectos manipulables, esto es, la concibe a su medida, Dios es relegado al olvido cuando -en el intento de tenerlo más cercano y accesible- se lo sustituye por entes de razón que excluyen su misterio. Este proceso no sería sino la traducción - a nivel conceptual- de esa arcaica tendencia creadora de dioses que, hoy como entonces, queriendo instalar al hombre en el corazón de lo sagrado, culmina con el exilio de Dios de todos los ámbitos de la experiencia humana. 
En este sentido entiendo yo la frase de Ricoeur que aboga por la necesidad de "dar muerte a los ídolo para recuperar el valor de nuestros símbolos", vale decir, por la necesidad de remontarnos en un proceso de -constructor, desde la unilateralidad de nuestros seudoconceptos, hasta la plenitud de los símbolos fundantes de nuestra cultura. No podemos olvidar, sin embargo, que el símbolo "da que pensar", nos acucia con su vocación de racionalidad y que, por consiguiente, ese remontar renovador desencadenará nuevamente una interpretación orientada hacia un telos conceptual. Estaríamos, así, aparentemente, amarrados a un continuo desplazamiento desde la oscura plenitud del símbolo hacia la empobrecida claridad del concepto, y desde ésta nuevamente hacia aquel, en una especie de actualización del mito del eterno retorno encaminada a reinstalarnos una y otra vez en la original plenitud del sentido.

\section{5.- CONCLUSIONES EN TORNO A LAS RELACIONES ENTRE RELIGIOSIDAD Y PROYECCION DE TRASMUNDOS}

Retomemos, ahora, los planteamientos de Nietzsche. Para él metafísica y nihilismo o muerte de Dios serían procesos equivalentes, por cuanto la proyección de trasmundos pertenecería a la esencia de la metafísica y de la religión, que no sería sino la versión popular de aquella. La metafísica así entendida representaría una de las posibilidades de sentido para la vida, una de las máscaras mediante las cuales el hombre hace tolerable la existencia, aquella que corresponde a una voluntad débil, a una vida enferma. Porque es sólo uno de los sentidos posibles, ella puede ser superada mediante una nueva máscara que cumpla la misma función, pero sin ese recurso a trasmundos que instituyera al sentido metafísico en vehículo del nihilismo.

Por otra parte, desde la perspectiva de Eliade y en contraposición a lo planteado por Nietzsche, la tendencia metafísica pertenece a la esencia del hombre. Podríamos decir que la humanidad de éste se define por una necesidad de sentido que lo impulsa a vivir en el más íntimo contacto posible con lo sagrado, que para él representa el ser verdadero, como medio de enraizar en lo eterno su propia finitud. Dicha tendencia no puede, por lo tanto, ser 
superada y se mantiene presente aun cuando, en épocas como la nuestra, ella sea relegada al subconsciente con las consiguientes expresiones enmascaradas a nivel de la conciencia.

Eliade describe, además, un fenómeno arcaico equivalente al de la muerte que se origina cuando éste se hace trascendente en relación al mundo, cuando efectivamente surge un trasmundo en el que el Dios ocioso fija su residencia. Ahora bien, la aparición de este trasmundo y la consecuente "muerte de Dios" estarían íntimamente relacionadas con las esencia de la religiosidad; esto es, con la tendencia a instalarse en lo sagrado como remedio frente al terror a la historia, puesto que dicha tendencia conduce a la hierofanización creciente que -en definitiva- provoca el alejamiento del Ser Supremo.

Llegamos, así, a la extraña conclusión de que el destacado fenomenólogo de las religiones parece coincidir con el moderno profeta de la muerte de Dios al entender ésta última como producto inevitable de la tendencia metafísica; con el agravante de que, para el primero, la necesidad de relacionar la propia finitud con lo eterno -la religiosidad-sería parte constitutiva de la esencia humana. ¿significaría ello que el nihilismo no es sólo el destino de la cultura occidental, como afirma Nietzsche, sino el inevitable destino del hombre como tal?

Por otra parte, el análisis que hicimos de los planteamientos de Ricoeur nos llevó a concluir que, en el discurso referente a Dios, el recorrido que va del símbolo al concepto representaría la traducción - a nivel conceptual- de la arcaica tendencia creadora de dioses. En esta forma, presenciaríamos nuevamente el fenómeno del alejamiento de Dios como aparente consecuencia de la religiosidad humana; ésta, en su afán de instalarnos en lo sagrado, parecería conducir insoslayablemente a la proyección de trasmundos con cuya nada el hombre terminaría por verse enfrentado.

Sin embargo, el mismo Ricoeur aporta una nueva perspectiva que permite distinguir entre la tendencia metafísica propiamente tal, vale decir, la necesidad de vivir en íntimo contacto con lo sagrado, y la proyección de trasmundos; ésta última no sería consecuencia necesaria de la primera, puesto que el trasmundo surgiría sólo cuando se olvida el insuperable carácter analógico de toda noción referente a lo sagrado. Permite hablar, por consiguiente, de una posible renuncia a dicha proyección sin que ello signifique desconocer o negar 
legitimidad a la religiosidad que Eliade describe como esencial al hombre. Ello sería factible en la medida en que -sin desconocer la vocación de racionalidad de nuestros símbolos- mantengamos presente también el elemento de indecibilidad que les es propio y que, precisamente, los constituye en aquello que da que pensar. En la medida en que comprendamos que la única manera de satisfacer la necesidad de vivir en intimo contacto con lo sagrado es recordando su absoluta trascendencia, no como parte de un trasmundo que responde a nuestra necesidad de fundamento, sino en relación a todos los posibles modos del decir. En la medida, en síntesis, en que seamos capaces de recuperar el discurso religioso como discurso poético, y de reconocer el valor revelador de la verdadmanifestación que le es propia, frente al valor manipulador de la verdad-adecuación que corresponde al discurso descriptivo. 